\title{
Effect of type of road humps on vehicular speeds on residential roads
}

\author{
Leksmono Suryo Putranto $^{1 *}$, and Kevin Kurniawan ${ }^{1}$ \\ ${ }^{1}$ University of Tarumanagara, Dept. Of Civil Engineering, 11440 Jakarta, Indonesia
}

\begin{abstract}
To reduce potential pedestrian fatalities, in residential road maximum speed is $30 \mathrm{~km} /$ hour. Apart from installing maximum speed signs, installing road humps may ensure speed reduction. This paper is intended to compare light vehicles and motorcycles speeds and speeds reductions due to road humps. Data collection was done in Modernland, Tanggerang City. Two road segments were observed, i.e. segments with standard and non-standard road humps. Observation was made in morning, noon and afternoon periods. A portable speed gun was used to measure the speed at about $50 \mathrm{~m}$ and $25 \mathrm{~m}$ before the road humps. Some mean difference statistical analyses were conducted for both speeds and speeds differences between different type of road humps and between pairs of observation periods. The 0.05 significant level was used. Surprisingly, mean of speeds differences $(50 \mathrm{~m}$ vs $25 \mathrm{~m})$ in standard road hump is significantly higher than in non-standard road hump.
\end{abstract}

\section{Introduction}

In residential roads, there are many daily domestic activities, such as, children crosing the roads to reach or return from school, senior citizens walking in the road (where pedestrian path is not available) to get fresh air in the morning, housewives crossing the roads to reach or return from grocery shops etc. To reduce potential pedestrian fatalities due to crash between motorized vehicles, in residential road maximum allowable speed is $30 \mathrm{~km} /$ hour. Therefore, apart from installing maximum speed signs, installing road humps may ensure speed reduction. This paper is intended to compare light vehicles and motorcycles speeds and speeds reductions due to road humps. Data collection was done in Modernland, Tanggerang City. Two road segments were observed, i.e. segments with standard and non-standard road humps.

\section{Literature reviews}

Road fatalities are strongly related with speeds. As understood, kinetic energy when a pedestrian was crashed by a vehicle is half the mass of the vehcile multiplied by the square

\footnotetext{
*Corresponding author : lexy_putranto@yahoo.co.id
} 
of the speed. Therefore part of kinetic energy from the speed is incredibly significant. So speed reduction will significantly help fatalities reduction [1]. Figure 1 shows the impact of speed on probability of pedestrian fatalities (accident causing death of road users). It can be seen that due to involvement of speeds in the magnitude of kinetic energy, there are huge increase of fatalities probability from almost zero to beyond $80 \%$ if speed is increased from $30 \mathrm{~km} /$ hour to $50 \mathrm{~km} /$ hour.

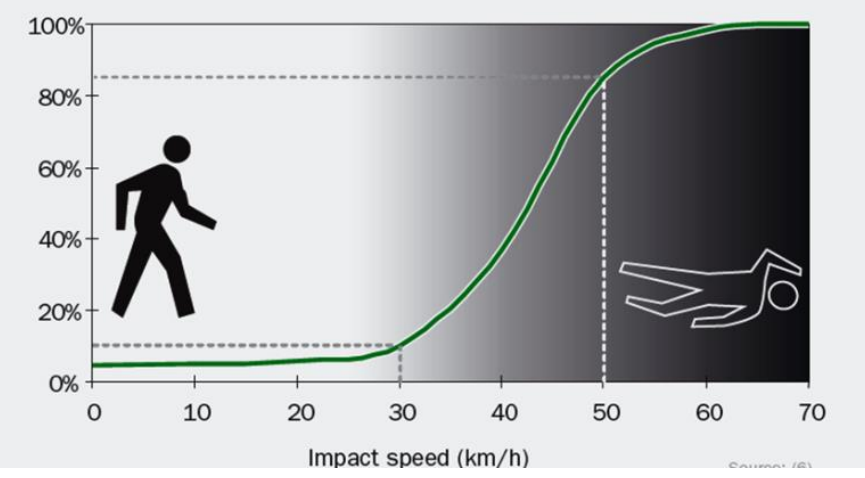

Figure 1 Impact of motorized vehicle speed to probability of pedestrian fatalities Source: OECD/ECMT Transport Research Centre [2]

Speed also determines stopping distance. Figure 2 shows and adaptation of Australian Transport Safety Bureau (ATSB) calculation of stopping distance [2]. Again we find benefit or speed reduction, i.e. required stopping distance reduction. For safely stop during driving at $30 \mathrm{~km} /$ hour, ones only required less than $15 \mathrm{~m}$ stopping distance (includes both reaction and braking distance). According to [3], speed limit is $30 \mathrm{~km} / \mathrm{hour}$.

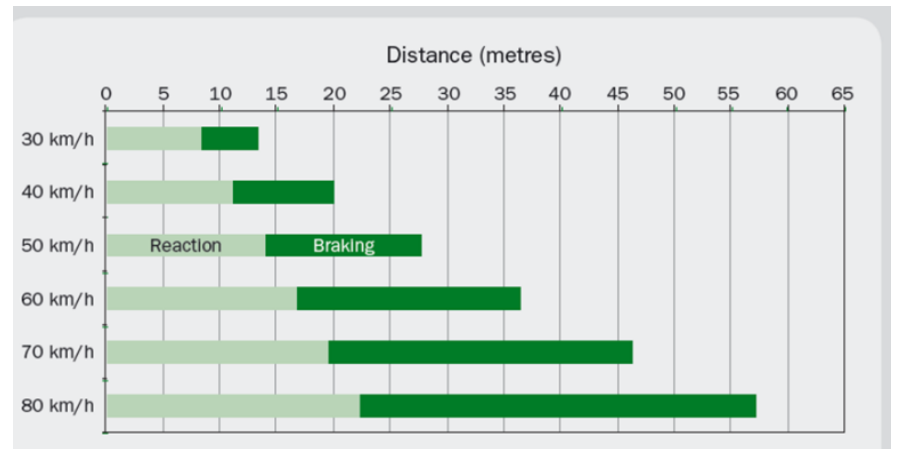

Figure 2 Effect of vehicular speeds on stopping distance Source: OECD/ECMT Transport Research Centre [2]

In Indonesia, road hump is regulated in [4]. In Chapter 2 Verse 1, road hump is defined as additional equipment on road which installed to force road user to reduce speed. Road hump should be installed perpendicularly to the road axis with certain width, thickness and gradient. The choice of material for road hump should consider road user safety.

In the same decree Chapter 4 Verse 1 regulate that road hump should be installed in

- Residential road

- Local road (class III C) 
- Roads with construction works

According to Chapter 5 Verse 1 of the same Decree, a road sign as shown in Figure 3 should be installed at certain distance before the road hump. This road sign is regulated in [5] on appendix 1 table 1 no. $6 \mathrm{~b}$.

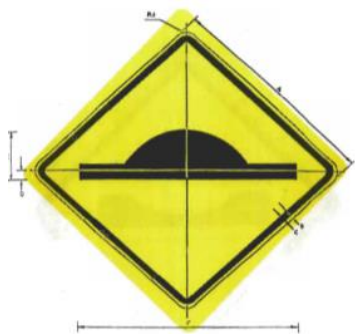

Figure 3 Road sign to indicate road hump ahead

According to Chapter 5 Verse 2 of [3], the road hump should be painted with incline white line road markings. Example and dimension of the marking is presented in Figure 4.

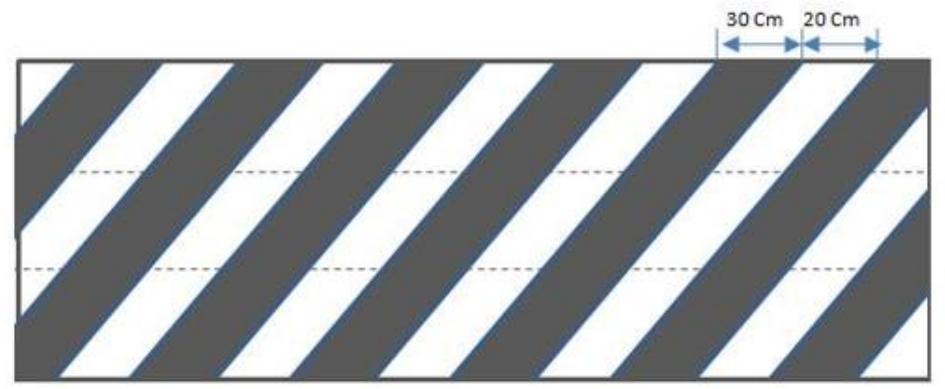

Figure 4 Example and dimension of road hump markings

According to Chapter 6 Verse 4 of [3], the dimension of Road Hump can be persented as Figure 5 and regulated as follow:

- The shape of road hump is trapezoid

- The maximum height is $12 \mathrm{~cm}$

- The maximum gradient of incline part is $15 \%$

- The minimum width of flat part is $15 \mathrm{~cm}$

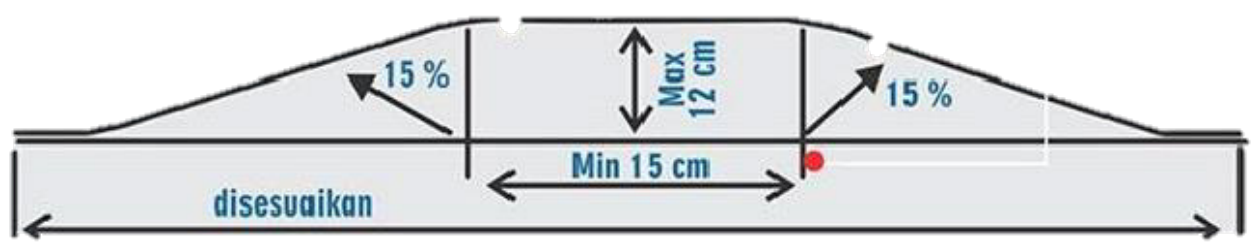

Figure 5 Standard road hump

Chapter 7 of [3] regulate the material of road hump can be the same with material of the road, can be from rubber or any other materials with similar effect and should consider road user safety. 


\section{Data collection method}

Data collection was done in Modernland, Tanggerang City. Two road segments were observed (Figure 6), i.e. segments with standard road hump (Figure 7) and segment with non-standard road humps (Figure 8). Observation was made in morning, noon and afternoon periods. Data Collection for speeds related to standard hump was done twice (Monday, 17 April 2017 and Tuesday 25 April 2017). Data Collection for speeds related to non-standard hump was also done twice (Tuesday, 18 April 2017 and Monday 24 April 2017). A portable speed gun was used to measure the speed at about $50 \mathrm{~m}$ and $25 \mathrm{~m}$ before the road humps.

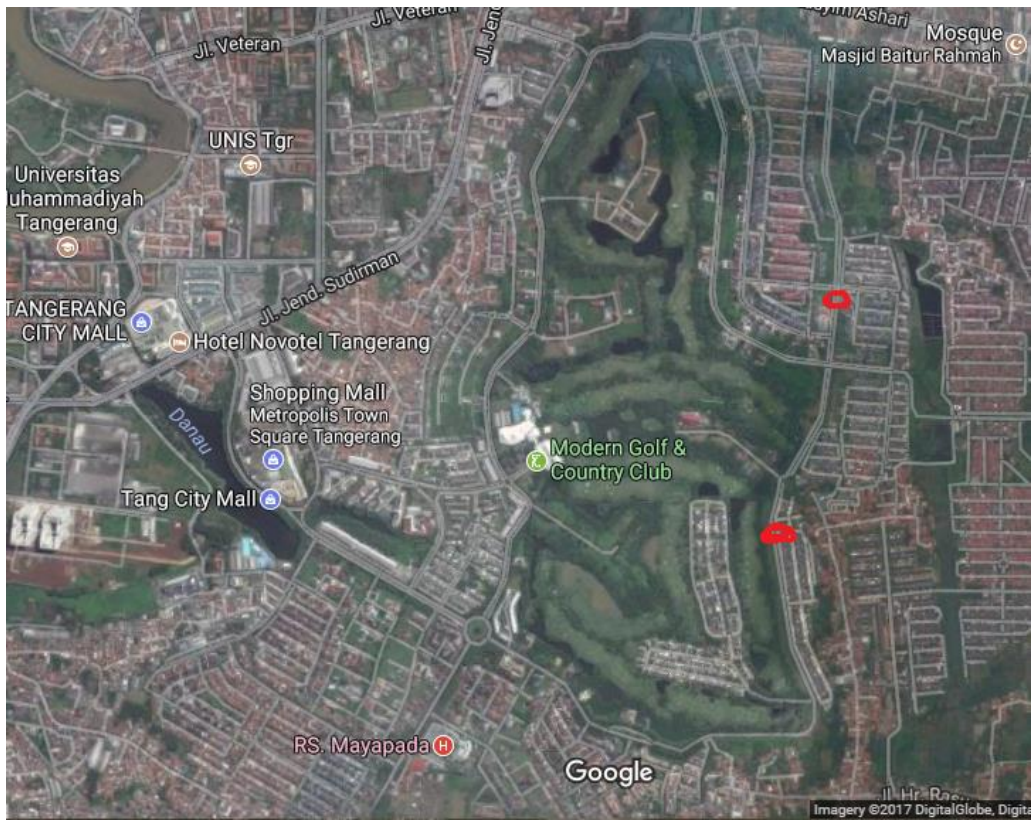

Figure 6 Observed segments in modern land indicated with red circles

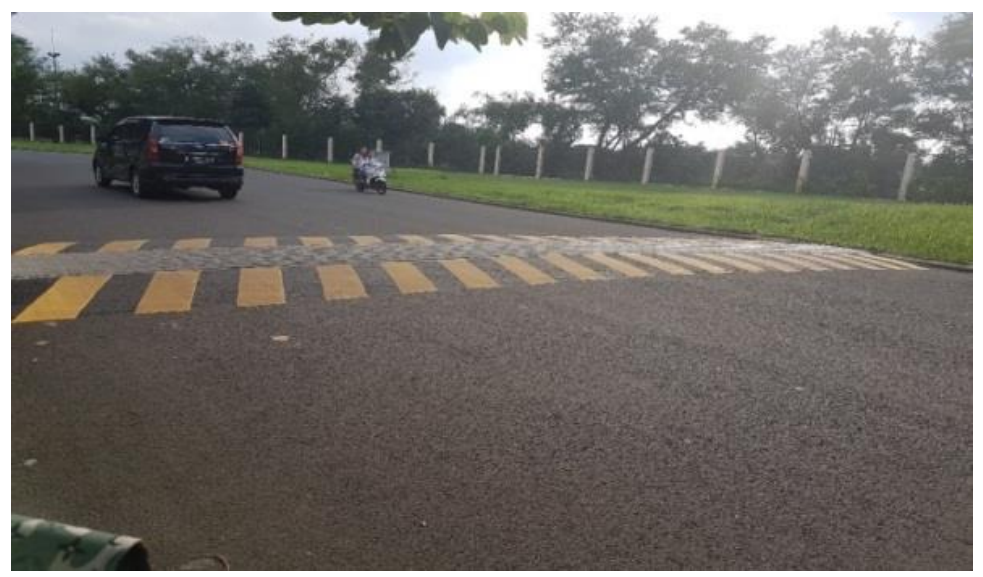

Figure 7. Observed segment with standard road hump 


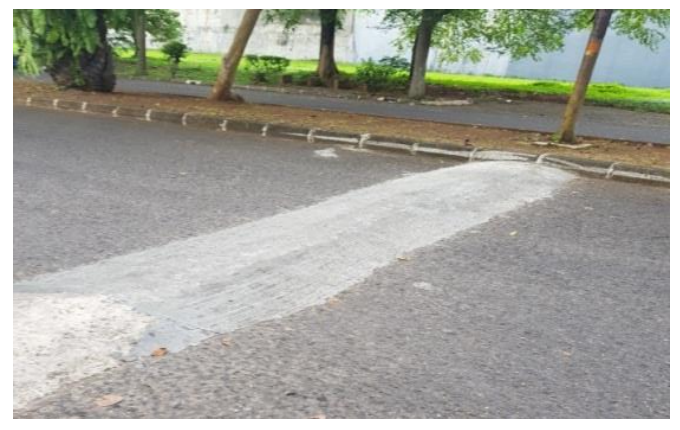

Figure 8. Observed segment with non-standard road hump

The speed gun was operated by a surveyor assisted by another surveyor who recorded the speed data manually. Two types of vehicle were observed, i.e. light vehicle and motorcycle. In each observation period the the length of observation was 60 minutes. Every one minute a pair of speed data (at $50 \mathrm{~m}$ and at $25 \mathrm{~m}$ before the speed hump) was observed. It can be either a light vehicle or a motorcycle, whichever measured first at that particular minute. Therefore number of observed light vehicles and motorcycles in each observation period is not equal.

\section{Method of data analysys}

All analyses were made seperately for light vehicles and motorcycles. Several mean difference statistical analyses were conducted at significant level of 0.05 to evaluate the followings:

1. Mean difference of speed reduction between vehicles travelling toward standar road hump and non-standard road hump.

2. Mean difference of speed reduction between pairs of observation period (morning-noon, morning-afternoon and noon-afternoon) within sthe same type of road hump.

3. Mean difference of speed at $50 \mathrm{~m}$ before standard road hump and non-standard road hump.

4. Mean difference of speed at $25 \mathrm{~m}$ before standard road hump and non-standard road hump.

\section{Results}

Table 1 summarizes various speeds related to standard road hump.Table 2 summarizes the same things related to non-standard hump.

Table 1. Summary of various speeds related to standard road hump

\begin{tabular}{|l|c|c|c|c|c|c|}
\hline \multirow{2}{*}{} & \multicolumn{3}{|c|}{ Speeds of Light Vehicles $(\mathrm{km} /$ hour) } & \multicolumn{3}{c|}{ Speed of Motorcycles (km/hour) } \\
\cline { 2 - 7 } & $50 \mathrm{~m}$ before & $25 \mathrm{~m}$ before & Reduction & $50 \mathrm{~m}$ before & $25 \mathrm{~m}$ before & Reduction \\
\hline $\mathrm{N}$ & 179 & 179 & 179 & 181 & 181 & 181 \\
\hline Mean & 39.09 & 14.77 & 24.32 & 45.14 & 15.93 & 29.20 \\
\hline Minimum & 31.00 & 12.00 & 16.00 & 35.00 & 13.00 & 19.00 \\
\hline Maximum & 51.00 & 19.00 & 34.00 & 53.00 & 20.00 & 37.00 \\
\hline
\end{tabular}


Table 2 Summary of Various Speeds Related to Non-Standard Road Hump

\begin{tabular}{|l|c|c|c|c|c|c|}
\hline \multirow{2}{*}{} & \multicolumn{3}{|c|}{ Speeds of Light Vehicles (km/hour) } & \multicolumn{3}{c|}{ Speed of Motorcycles (km/hour) } \\
\cline { 2 - 7 } & $50 \mathrm{~m}$ before & $25 \mathrm{~m}$ before & Reduction & $50 \mathrm{~m}$ before & $25 \mathrm{~m}$ before & Reduction \\
\hline $\mathrm{N}$ & 202 & 202 & 202 & 158 & 158 & 158 \\
\hline Mean & 34.93 & 14.79 & 20.13 & 37.27 & 15.16 & 22.11 \\
\hline Minimum & 30.00 & 12.00 & 14.00 & 30.00 & 3.00 & 16.00 \\
\hline Maximum & 43.00 & 19.00 & 26.00 & 49.00 & 20.00 & 30.00 \\
\hline
\end{tabular}

It can be seen that in general speeds $50 \mathrm{~m}$ before the standard road hump were higher than speeds $50 \mathrm{~m}$ before to non-standard road hump both for light vehicles and motorcycles. As the speeds $25 \mathrm{~m}$ before both type of road humps were about the same then the speeds reductions before standard road hump were higher than speed reductions before the nonstandard road hump for both light vehicles and motorcycles. There is no logical nor theoretical explanation regarding these consistent results. It is also found that motorcycles speeds were higher than light vehicles. It should be noted that all mean speeds (and offcourse maximum speeds) at $50 \mathrm{~m}$ before any types of road hump were higher than 30 $\mathrm{km} /$ hours (beyond the regulation for residential road speed limit). Even the minimum speeds at $50 \mathrm{~m}$ before any types of road hump were as high as $30 \mathrm{~km} /$ hour. Therefore additional road humps might be justified along with additional speed limit sign and public awareness program to reduce speed there.

For further tables on this paper RH stands for Road Hump, SRH stands for Standard Road Hump and NSRH standsfor Non-Standar Road Hump. Table 3 summarizes the mean difference test of speed reduction between standard road hump and non-standard road hump for morning, noon and afternoon observation periods for both light vehicles and motorcycles. It can be seen that all test results were significant at 0.05 and with higher mean of speed reduction for standard road hump meaning that mean of speed reduction for standard road hump is significantly higher than mean of speed reduction for non-standard road hump for all type and vehicles and for all observation periods.Table 4 summarized similar things with Table 3 except that it discuss speeds $50 \mathrm{~m}$ before the road hump. Table 5 summarized similar things with Table 3 except that it discuss speeds $25 \mathrm{~m}$ before the road hump. All analyses in Table 4 were significant at 0.05 and although not all analyses in Table 5 were significat at 0.05 but the mean differences were relatively low. The test results in Table 4 and Table 5 correspond with the results in Table 3, i.e. the significant speeds reductions were result of relatively high mean value of speeds at $50 \mathrm{~m}$ before road hump and relatively low speeds at $25 \mathrm{~m}$ before road hump.

Table 3 Mean Difference of Speed Reduction between SRH and NSRH

\begin{tabular}{|l|c|c|c|c|c|c|}
\hline \multirow{2}{*}{} & \multicolumn{6}{|c|}{ Mean of Speed Reduction (km/hour) } \\
\cline { 2 - 7 } & \multicolumn{3}{|c|}{ Light Vehicles } & \multicolumn{4}{c|}{ Motorcycles } \\
\cline { 2 - 7 } & Morning & Noon & Afternoon & Morning & Noon & Afternoon \\
\hline N SRH & 58 & 65 & 56 & 62 & 55 & 64 \\
\hline N NSRH & 74 & 63 & 65 & 46 & 57 & 55 \\
\hline Mean SRH & 24.0466 & 24.8153 & 24.0446 & 28.8952 & 29.6636 & 29.1094 \\
\hline Mean NSRH & 20.0541 & 20.5556 & 19.8308 & 22.4130 & 22.1316 & 21.8545 \\
\hline Mean Difference & 3.9925 & 4.2598 & 4.2138 & 6.4821 & 7.5320 & 7.2548 \\
\hline Significant Level & $<0.001$ & 0.001 & $<0.001$ & $<0.001$ & $<0.001$ & $<0.001$ \\
\hline Significant? (Yes/No) & Yes & Yes & Yes & Yes & Yes & Yes \\
\hline
\end{tabular}


Table 4 Mean difference of speed at $50 \mathrm{~m}$ before RH between SRH and NSRH

\begin{tabular}{|l|c|c|c|c|c|c|}
\hline \multirow{2}{*}{} & \multicolumn{6}{|c|}{ Mean of Speed Reduction (km/hour) } \\
\cline { 2 - 7 } & Morning & Noon & Afternoon & Morning & Noon & Afternoon \\
\cline { 2 - 7 } & 58 & 65 & 56 & 62 & 55 & 64 \\
\hline N SRH & 74 & 63 & 65 & 46 & 57 & 55 \\
\hline Mean SRH & 39.2190 & 39.4000 & 38.6250 & 39.2190 & 44.5091 & 44.8125 \\
\hline Mean NSRH & 35.6216 & 35.4444 & 33.6462 & 35.6216 & 37.7193 & 36.8727 \\
\hline $\begin{array}{l}\text { Mean } \\
\text { Difference }\end{array}$ & 3.5973 & 3.9556 & 4.9788 & 3.5973 & 6.7897 & 7.9397 \\
\hline $\begin{array}{l}\text { Significant } \\
\text { Level }\end{array}$ & $<0.001$ & $<0.001$ & $<0.001$ & $<0.001$ & $<0.001$ & $<0.001$ \\
\hline $\begin{array}{l}\text { Significant? } \\
\text { Yes/No) }\end{array}$ & Yes & Yes & Yes & Yes & Yes & Yes \\
\hline
\end{tabular}

Table 5. Mean difference of speed at $25 \mathrm{~m}$ before RH between SRH and NSRH

\begin{tabular}{|l|c|c|c|c|c|c|}
\hline & \multicolumn{6}{|c|}{ Mean of Speed Reduction (km/hour) } \\
\cline { 2 - 7 } & Morning & Noon & Afternoon & Morning & Noon & Afternoon \\
\cline { 2 - 7 } & 58 & 65 & 56 & 62 & 55 & 64 \\
\hline N SRH & 74 & 63 & 65 & 46 & 57 & 55 \\
\hline N NSRH & 15.1724 & 14.5846 & 14.5804 & 16.3306 & 15.7545 & 15.7031 \\
\hline Mean SRH & 15.5676 & 14.8889 & 13.8154 & 14.8043 & 15.5877 & 15.0182 \\
\hline Mean NSRH & -0.3951 & 0.2440 & 0.7649 & 0.049 & 0.1668 & 0.6849 \\
\hline $\begin{array}{l}\text { Mean } \\
\text { Difference }\end{array}$ & 0.065 & 0.244 & $<0.001$ & 0.001 & 0.573 & 0.03 \\
\hline $\begin{array}{l}\text { Significant } \\
\text { Level }\end{array}$ & No & No & Yes & Yes & No & Ya \\
\hline $\begin{array}{l}\text { Significant? } \\
\text { (Yes/No) }\end{array}$ & & & & & & \\
\hline
\end{tabular}

Tables 6 through 8 shows that there were almost no significant mean difference between speed reduction between pair of observation periods (morning-noon, noon-afternoon and morning-afternoon). The original plan of morning period was $06.00-07.00$, noon period was 12.00-13.00 and afternoon period was 17.00-18.00 to describe morning peak hour, noon off-peak hour and afternoon peak hour. However, the survey team misunderstood the instruction and instead conduct the morning period at 10.00-11.00 and afternoon period at 15.00-16.00. These periods of the day might be considered to belong to off-peak hours and this may cause no significant difference of speed reduction.

Table 6. Mean difference of speed reduction between morning and noon observation

\begin{tabular}{|l|c|c|c|c|}
\hline \multirow{2}{*}{} & \multicolumn{3}{|c|}{ Mean of Speed Reduction (km/hours) } \\
\cline { 2 - 5 } & Light Veeicles & \multicolumn{2}{c|}{ Motorcycles } \\
\cline { 2 - 5 } & SRH & NSRH & SRH & NSRH \\
\hline N Morning & 58 & 74 & 62 & 46 \\
\hline N Noon & 65 & 63 & 55 & 57 \\
\hline Mean Morning & 24.0466 & 20.0541 & 28.8952 & 22.4130 \\
\hline Mean Noon & 24.8154 & 20.5556 & 29.6636 & 22.1316 \\
\hline Mean Difference & -0.7688 & -0.5015 & 0.7684 & 0.2814 \\
\hline Significant Level & 0.248 & 0.166 & 0.248 & 0.598 \\
\hline Significant? (Yes/No) & No & No & No & No \\
\hline
\end{tabular}


Table 7. Mean difference of s'peed reduction between noon and afternoon observation

\begin{tabular}{|l|c|c|c|c|}
\hline \multirow{2}{*}{} & \multicolumn{3}{|c|}{ Mean of Speed Reduction (km/hours) } \\
\cline { 2 - 5 } & \multicolumn{2}{|c|}{ Light Vehicles } & \multicolumn{2}{c|}{ Motorcycles } \\
\cline { 2 - 5 } & SRH & NSRH & SRH & NSRH \\
\hline N Noon & 65 & 63 & 55 & 57 \\
\hline N Afternoon & 56 & 65 & 64 & 55 \\
\hline Mean Noon & 24.8154 & 20.5556 & 29.6636 & 22.1316 \\
\hline Mean Afternoon & 24.0446 & 19.8308 & 29.1094 & 21.8545 \\
\hline Mean Difference & 0.7707 & 0.7247 & 0.5542 & 0.2770 \\
\hline Significant Level & 0.220 & 0.024 & 0.384 & 0.598 \\
\hline Significant? (Yes/No) & No & Yes & No & No \\
\hline
\end{tabular}

Table 8. Mean difference of speed reduction between morning and afternoon observation

\begin{tabular}{|l|c|c|c|c|}
\hline \multirow{2}{*}{} & \multicolumn{3}{|c|}{ Mean of Speed Reduction (km/hours) } \\
\cline { 2 - 5 } & \multicolumn{2}{|c|}{ Light Vehicles } & \multicolumn{2}{c|}{ Motorcycles } \\
\cline { 2 - 5 } & SRH & NSRH & SRH & NSRH \\
\hline N Morning & 58 & 74 & 62 & 46 \\
\hline N Afternoon & 56 & 65 & 64 & 55 \\
\hline Mean Morning & 24.0466 & 20.0541 & 28.8952 & 22.4130 \\
\hline Mean Afternoon & 24.0446 & 19.8308 & 29.1094 & 21.8545 \\
\hline Mean Difference & 0.0019 & 0.2232 & -0.2142 & 0.5585 \\
\hline Significant Level & 0.998 & 0.564 & 0.730 & 0.313 \\
\hline Significant? (Yes/No) & No & No & No & No \\
\hline
\end{tabular}

\section{Conclusions and recommendations}

From the results of the analyses, it can be concluded that:

1. Mean of speed reduction for standard road hump is significantly higher than mean of speed reduction for non-standard road hump for all type and vehicles and for all observation periods.

2. There were no significant difference of mean of speed reduction between pairs of observation period because of incorrect schedule of morning and afternoon observation (ending up with all observation periods belong to off-peak hours).

From the results of the analyses that showing relatively high speed exceeding speed limit for residential are, in Modern Land it is recommended to add more road humps, install speed limit signs and conduct public awaraness to reduce speed of motorized vehicles. For further research, it is important to conduct the survey at morning and afternoon peak hours to understand possible difference in the result compare to the off-peak hour. It is also recommended to measure the speed after the road hump to determine the suggested distance between adjacent road humps. 


\section{References}

1. __ Global Road Safety Partnership., Speed management: a road safety manual for decision-makers and practitioners (2008)

2. —_ OECD/ECMT Transport Research Center., Speed Management report (2006).

3. —— Minister of Transportation Decree No. 111 Year 2015 on Procedure of Speed Limit Determinaton for residential road (2015)

4. _— Minister of Transportation Decree No.3 Year 1994 on Road User Control Equipment, (1994)

5. __ Minister of Transportation Decree No. 61 Year 1993 on Traffic Signs on Street, (1993) 